\title{
Bare and Not-So-Bare Nouns and the Structure of NP
}

\author{
Lisa Lai-Shen Cheng \\ Rint Sybesma
}

\begin{abstract}
This article examines the distribution and interpretational variability of bare nouns and [classifier+ noun] phrases in Cantonese and Mandarin. We argue that bare nouns are never bare in structure and that [classifier+ noun] phrases may have more structure than just Classifier Phrase. We show that the lack of articles and number morphology in Cantonese/Mandarin leads to many interesting differences between Chinese-type languages and English-/Italian-type languages.
\end{abstract}

Keywords: Cantonese, classifiers, count nouns, Mandarin, mass nouns, noun interpretation, NP structure

\section{Introduction}

It is well known that Chinese languages allow bare nouns to appear as arguments. In this article we discuss in detail the distribution and interpretation of bare nouns in Mandarin and Cantonese. We also examine [classifier + noun] $([\mathrm{Cl}+\mathrm{N}])$ phrases in these two Chinese languages because they display interesting similarities to, and differences from, bare nouns. More specifically, we focus on the following issues:

Various interpretations. Bare nouns in Mandarin and Cantonese can have more than one interpretation. In postverbal position, for instance, Mandarin bare nouns can be interpreted as indefinite (1a), definite (1b), or generic (1c). ${ }^{1}$ In preverbal position, they can be interpreted as definite $(2 b)$ or as generic $(2 c)$, but not as indefinite $(2 a){ }^{2}(\operatorname{sFP}=$ sentence-final particle)

Sybesma's research was financially supported by the Foundation for Language, Speech, and Logic, which is funded by the Dutch Organization for Scientific Research. We received additional financial support from the International Institute for Asian Studies, Leiden, The Netherlands, and the Netherlands Graduate School in Linguistics, Utrecht, The Netherlands. All the financial support is gratefully acknowledged. Some of the research reported here was presented at workshops, conferences, and seminars in Hong Kong, Paris, Tilburg, Berlin, Irvine, Leiden, Groningen, and Ithaca. We thank the audiences for comments and discussion. We would furthermore like to thank the following colleagues for their input and helpful suggestions: Crit Cremers, Jenny Doetjes, Teun Hoekstra, Martin Honcoop, Richard Kayne, Utpal Lahiri, Audrey $\mathrm{Li}$, Jane Tang, and Dylan Tsai. We also thank two anonymous reviewers for very insightful comments and suggestions.

We dedicate this article to the memory of Teun Hoekstra.

${ }^{1}$ For the definite interpretation of bare nouns in cases like (1b), see Sybesma 1992:176-178 and Krifka 1992. For general discussion of noun phrase interpretation in Mandarin, see Mullie 1930, Li and Thompson 1975, 1981, Travis 1984, and Sybesma 1992, 1999.

${ }^{2}$ A reviewer notes that there are two exceptions to the claim that indefinite preverbal subjects are excluded. First, in answering the question 'Who came?', Mandarin speakers can say Guizi lai-le 'Foreigners came'. Second, in some contexts involving numerals such as 'Five persons fit into one car', the subject appears to be indefinite. Regarding the first case, informants whom we consulted consistently indicated that the bare noun in such a case has a definite reading, 
(1) a. Hufei mai shu qu le.

Hufei buy book go SFP

'Hufei went to buy a book/books.'

b. Hufei he-wan-le tang.

Hufei drink-finish-LE soup

'Hufei finished the soup.'

c. Wo xihuan gou.

I like dog

'I like dogs.'

(2) a. Gou yao guo malu.

dog want cross road

'The dog wants to cross the road.' not: 'A dog wants to cross the road.'

b. Gou jintian tebie tinghua.

dog today very obedient

'The dog/dogs was/were very obedient today.'

c. Gou ai chi rou.

dog love eat meat

'Dogs love to eat meat.'

The immediate question that arises is, How do we account for this variety of interpretations and the restriction associated with indefinite bare nominals? (We should note that in this article, except for a brief comment in section 5, we will not discuss demonstratives.)

Differences between Cantonese and Mandarin. When it comes to the distribution and interpretation of bare nouns, the Cantonese pattern is almost the same as the Mandarin pattern illustrated in (1), the crucial exception being that Cantonese bare nouns cannot be interpreted as definite. Instead, Cantonese uses the $[\mathrm{Cl}+\mathrm{N}]$ combination (see also Leung 1980). In other words, in Cantonese, just as in Mandarin, bare nouns can be indefinite postverbally (3a) but not preverbally (4a), and generic in both positions (3c)/(4c). Definite counterparts of (1b) and (2b), however, are different in Cantonese: instead of bare nouns, Cantonese uses $[\mathrm{Cl}+\mathrm{N}]$, as illustrated in $(3 \mathrm{~b})$ and (4b).

(3) a. Wufei heoi maai syu.

Wufei go buy book

'Wufei went to buy a book/books.'

b. Wufei jam-jyun *(wun) tong la.

Wufei drink-finish CL soup SFP

'Wufei finished drinking the soup.'

and some indicated that a type/kind interpretation is possible. This can be clearly illustrated with the following answer to 'Who came?': Xuesheng lai-le 'The student came'. Thus, it does not appear to be the case that focus can freely license indefinite NPs. Tsai (1998) claims that the second case involves what he calls "cardinal subjects," which must express quantity. For discussion, see Tsai 1998 and Li 1998. 
c. Ngo zungji gau.

I like dog

'I like dogs.'

(4) a. *Gau soeng gwo maalou.

dog want cross road

'A dog wants to cross the road.'

b. Zek gau gamjat dakbit tengwaa.

CL dog today special obedient

'The dog is specially obedient today.'

c. Gau zungji sek juk.

dog like eat meat

'Dogs love to eat meat.'

It should be noted that $[\mathrm{Cl}+\mathrm{N}]$ phrases such as the ones in (3b) and (4b) can only be singular, unlike definite bare nouns, which can be plural (see (2) and the discussion in section 3.1). Moreover, in addition to a definite reading, Cantonese $[\mathrm{Cl}+\mathrm{N}]$ can receive an indefinite, nonspecific reading, as in (5); however, a generic interpretation for $[\mathrm{Cl}+\mathrm{N}]$ is impossible, as in $(6 \mathrm{a}-\mathrm{b})$ (see also section 3.3).

(5) Ngo soeng maai bun syu (lei taai).

I want buy CL book come read

'I want to buy a book (to read).'

(6) a. Zek gau zungji sek juk.

CL dog like eat meat

'The dog likes to eat meat.' not: 'Dogs like to eat meat.'

b. Ngo zungji tong zek gau waan.

I like with CL dog play

'I like to play with the dog.' not: 'I like to play with dogs.'

This brings us to a second difference between Cantonese and Mandarin. As shown in (7), contrary to what is generally assumed (see, e.g., Li and Thompson 1981:104, Tang 1990), it is not the case that in Mandarin a classifier must cooccur with an overt numeral or a demonstrative. The example in (7) shows that Mandarin also has $[\mathrm{Cl}+\mathrm{N}]$ phrases; in section 3.2 we provide evidence that these are not cases of phonological reduction.

(7) Wo xiang mai ben shu.

I would-like buy CL book

'I would like to buy a book.'

However, whereas in Cantonese $[\mathrm{Cl}+\mathrm{N}]$ phrases can receive either a definite or an indefinite reading, in Mandarin they are restricted to an indefinite interpretation: they cannot be interpreted as definite (or generic).

In sum, bare nouns and $[\mathrm{Cl}+\mathrm{N}]$ phrases have the following interpretational possibilities in Cantonese (C) and Mandarin (M): 
(8)

\begin{tabular}{llll} 
& Indef & Def & Gen \\
\hline Bare nouns & $\mathrm{M} / \mathrm{C}$ & $\mathrm{M}$ & $\mathrm{M} / \mathrm{C}$ \\
{$[\mathrm{Cl}+\mathrm{N}]$} & $\mathrm{M} / \mathrm{C}$ & $\mathrm{C}$ & - \\
\hline
\end{tabular}

The difference between the two languages centers on the definite interpretation of bare nouns and $[\mathrm{Cl}+\mathrm{N}]$ phrases: in Mandarin only bare nouns can be definite, and in Cantonese only $[\mathrm{Cl}+\mathrm{N}]$ phrases can. In turn, the difference between bare nouns and $[\mathrm{Cl}+\mathrm{N}]$ phrases centers on the definite interpretation and the generic interpretation. Although both bare nouns and $[\mathrm{Cl}+\mathrm{N}]$ phrases allow both a definite and an indefinite interpretation, they can't do both in both languages, as just noted. Furthermore, $[\mathrm{Cl}+\mathrm{N}]$ cannot have a generic interpretation in either language.

The question of how these differences come about is certainly connected to the earlier question of how the various interpretations arise.

Chinese NP denotation. The third issue concerns the licensing of bare nouns. The fact that Chinese bare nouns can appear as arguments is interesting in view of the claim made by Stowell (1989), Szabolcsi (1994), Longobardi (1994), and others that only DPs can function as arguments. If this is true, then bare nouns in Chinese must involve more structure than just the bare $\mathrm{N}$ (or the bare NP). In contrast, Chierchia $(1995,1998)$ proposes that Chinese nouns differ from nouns in languages like English in that they are arguments (of type $\langle\mathrm{e}\rangle$ ) rather than predicates (of type $\langle e, t\rangle)$ and thus can appear bare.

This article is organized as follows. In section 2 we investigate some of the general issues mentioned in the previous paragraph. In section 3 we address some of the interpretational issues, particularly the indefinite and definite interpretation of bare nouns and $[\mathrm{Cl}+\mathrm{N}]$ phrases; we look further into the differences between Cantonese and Mandarin; and we discuss generics and specificity. In sections 4 and 5 we briefly touch on more general issues, such as the function of DP and some consequences of our proposals for the analysis of Chinese pronouns and demonstratives, and for languages with articles such as Italian and English.

\section{Preliminary Discussion: Some General Issues}

\subsection{Distribution and Interpretation}

As shown in (1) and (2), bare nouns in Mandarin can receive an indefinite interpretation only in postverbal position; in preverbal position this is impossible. This fact parallels the distribution of bare nouns in some Romance and Germanic languages discussed by Longobardi (1994). For instance, just as in Mandarin, bare nominals (mass nouns) in Italian can be interpreted as indefinite and are restricted to postverbal position (as in (9), Longobardi's (14)). ${ }^{3}$

\footnotetext{
${ }^{3}$ An obvious difference between Italian (and most other Germanic and Romance languages) and Mandarin is, of course, that in the latter but not the former, bare nominals can have a definite interpretation (both preceding and following the verb). For a definite interpretation to be possible, languages like English and Italian must use the definite article. See also sections 3.1 and 5 .
} 
(9) a. *Acqua viene giù dalle colline. water comes down from-the hills

b. Viene giù acqua dalle colline. comes down water from-the hills

c. Ho preso acqua dalla sorgente.

I took water from-the spring

The proposal Longobardi (1994) develops with regard to the distribution and interpretation of bare nouns in Germanic and Romance can be informally summarized as follows. The core generalization is that bare nouns with an indefinite interpretation are restricted to lexically governed positions (essentially, object position). Longobardi claims that bare nouns are not really bare: they are embedded in a full-fledged DP structure, with an empty D head. The presence of an empty D head leads to an explanation for both the indefinite interpretation and the restricted distribution. Longobardi maintains that an empty D head is associated with an existential reading (see also Chierchia 1998). Further, an empty D is just like any other empty category in that it must be lexically governed. ${ }^{4}$ Hence, bare nouns with an indefinite reading are restricted to lexically governed positions.

However, there are other interpretations of bare nouns, involving generics and proper names, that are not restricted to lexically governed positions. Longobardi accounts for these bare nouns by arguing that N-to-D movement has taken place (see also, e.g., Ritter 1989), either in overt syntax or at LF. The N-to-D movement thus has two effects: (a) because $\mathrm{N}$ fills the D position, the bare noun is no longer distributionally restricted to lexically governed positions; and (b) because $\mathrm{D}$ is not empty, the noun phrase is no longer interpreted existentially.

The idea of an empty D is partly motivated by the theoretical claim, also made by Szabolcsi (1987, 1994:181) and Stowell (1989), that only DPs can function as arguments: NPs are predicates or "propositions," and D turns them into arguments. Szabolcsi claims that in this respect typical Ds like articles are similar to complementizers, and both are "subordinators." In addition, D has an individualizing or singularizing function (Longobardi 1994:634): it has the ability to pick out a single instance of whatever is described by NP (see also Higginbotham 1985). This function, we think, is connected to the similar, though not identical, assumption that D has the function of mediating between the description (predication) provided by the NP and whatever specific entity in the real world the description is applied to. This function, perhaps a discourse function, we will refer to as the deictic function of $\mathrm{D}$.

\footnotetext{
${ }^{4}$ The lexical government requirement can be reinterpreted as an LF licensing requirement within the Minimalist Program (see also Chierchia 1998). That is, the empty D must be licensed by a lexical head (via LF incorporation) (e.g., a V). This maintains the subject-object asymmetry.

${ }^{5}$ In Longobardi's analysis, there is a distinction between proper names and common nouns. In Italian, though proper names can undergo N-to-D movement, common nouns cannot. This Longobardi attributes to the nature of common nouns; they need to refer to a kind and therefore must stay in N. However, N-to-D movement of common nouns is apparently possible in some Scandinavian languages. Longobardi resolves this contrast by assuming a distinction between adjoining $\mathrm{N}$ to an operator $\mathrm{D}$ and substituting $\mathrm{N}$ for a nonoperator $\mathrm{D}$ (overtly or covertly). We will come back to this point when we discuss definite bare nouns in Chinese.
} 
In section 4 we turn to general questions pertaining to the nature and function of D and DP, and in section 2.2.2 we consider what $\mathrm{D}$ is in Chinese. First, however, we introduce some general features of the Chinese noun phrase.

\subsection{Mass Nouns and Count Nouns}

2.2.1 Classifiers In English, mass nouns require a measure phrase in order to be countable ( $a$ glass of milk, two loaves of white bread, every grain of sand). An important property of Chinese is that all nouns, including those whose counterparts in English would be count nouns, are like mass nouns in needing a measure phrase or classifier (both of which we will refer to as "classifiers"). (10) and (11) provide typical examples of Mandarin classifiers. ${ }^{6}$

(10) a. san ping jiu

three bottle liquor

'three bottles of liquor'

b. san ba mi

three handful rice

'three handfuls of rice'

c. san wan tang

three bowl soup

'three bowls of soup'

(11) a. san ge ren

three CL people

'three persons'

b. san zhi bi

three $\mathrm{CL}$ pen

'three pens'

c. san ben shu

three CL book

'three books'

The pattern seems to be the same for all of these phrases: in Chinese, just as one must say 'three units (of) liquor', one must say 'three units (of) people'. This has led some linguists to propose that, indeed, all nouns in Chinese are mass nouns. Let us dwell for a moment on whether this is so.

Although it is an important function of all classifiers that they make the noun with which they are associated countable, it has been argued (by Tai and Wang (1990) and Croft (1994),

\footnotetext{
${ }^{6}$ Some abstract nouns may fall outside of this description (Chao 1968). In particular, even though some abstract nouns such as taidu 'attitude' appear to allow the classifier zhong 'kind', derived nominals are more resistant to classifiers: for instance, liaojie 'understanding', ?*zhe-zhong liaojie 'this kind of understanding', *zhe-ge liaojie 'this understanding'.
} 
among many others) that classifiers can roughly be divided into two groups: classifiers that create a unit of measure, and those that simply name the unit in which the entity denoted by the noun naturally occurs (see Peyraube 1998 for historical support for distinguishing the two types). Liquor, rice, and soup do not come naturally in bottles, handfuls, or bowls; instead, they can come in, say, glasses, liters, and cups. Indeed, nouns like this do not have a built-in semantic partitioning; that is why they are called mass nouns. ' In contrast, ping 'bottle', ba 'handful', and wan 'bowl' in (10) create units by which the amount of liquor, rice, and soup is measured. The nouns in (11) seem different in this respect. Books, people, and pens provide natural units by which they can be counted: individual volumes, persons (one head, one heart, one spine), and pens; this is why nouns like book, person, and pen are called count nouns. As a result, classifiers like ge, zhi, and ben (as in $(11 \mathrm{a}-\mathrm{c})$ ) do not create units, they simply name them. In Cheng and Sybesma, to appear, we refer to the classifiers that create a unit of measure as massifiers (short for mass-classifiers), and to the ones that simply name the unit of natural semantic partitioning as count-classifiers. We continue to use these terms here.

Note that massifiers do not occur only with mass nouns. Since they create units of measure, they can also occur with nouns that have a natural partitioning as part of their semantics ( $a$ group of people, a pound of beans); see footnote 7 .

Turning to the question of whether all nouns in Chinese are mass nouns, it is clear from the above discussion that the distinction between the two types of classifiers is made with explicit reference to two different types of nouns: nouns that come with a built-in semantic partitioning and nouns that do not-that is, count nouns and mass nouns. If count-classifiers are assumed to merely name the units in which certain phenomena naturally present themselves, then these units preexist as part of the semantics of the nouns the count-classifiers cooccur with.

In other words, the count/mass distinction is clearly reflected in the classifier system. In Cheng and Sybesma, to appear, we show that there are (at least) two grammatical processes that are sensitive to the type of classifier used. First, a modification marker de can intervene in $[$ massifier $+N$ ] sequences but not in [count-classifier $+N$ ] sequences, as the contrast between (12) and (13) shows (see also, e.g., Chao 1968, Paris 1981, and Sybesma 1992).
(12) a. san bang (de) rou
three CL-pound DE meat
'three pounds of meat'
b. liang xiang (de) shu
two CL-box DE book
'two boxes of books'

\footnotetext{
${ }^{7}$ Arguably, words like 'rice' do have a natural partitioning, namely, grains. See Cheng and Sybesma, to appear, for discussion. 'Rice' can be counted according to $l i$ 'grain' or wan 'bowl', and in that sense it is similar to 'people', which can be counted by ge 'classifier for people' (a count-classifier) and qun 'group' (a massifier).
} 


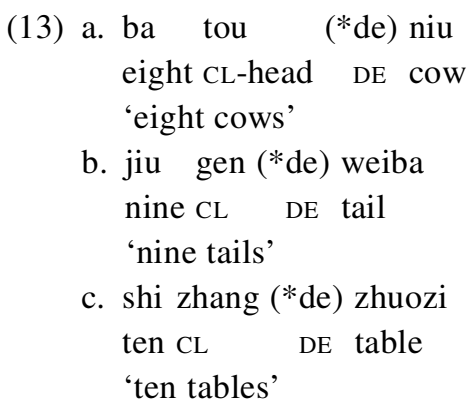

Second, certain adjectives can modify massifiers but not count-classifiers (see also Tang 1990), as shown in (14) and (15).

(14) a. yi da zhang zhi

one big CL-sheet paper

'one large sheet of paper'

b. na yi xiao xiang shu

that one small cL-box book

'that one small box of books'

(15) a. *yi da zhi gou ${ }^{8}$

one big CL dog

b. *yi da wei laoshi

one big $\mathrm{CL}$ teacher

It is thus clear that the count/mass distinction does play a role in Chinese grammar (see also Doetjes 1997). Just like some nouns in languages like English, some nouns in Chinese are inherently semantically partitioned into discrete units (i.e., count nouns), and others are not (i.e., mass nouns). Let us say that this cognitive reality is represented in the semantics of the noun in all these languages. What distinguishes Chinese from languages like English is that in Chinese the grammatical (or syntactic) reflex of the count/mass distinction is not at the level of the noun as it is in Indo-European languages, where mass nouns and count nouns each have their own set of grammatical properties. Instead, it is at the level of the classifier: Chinese has count-classifiers and mass-classifiers, each set with its own grammatical properties.

Even so, all nouns in Chinese, the ones with the built-in partitioning as well as the ones without, need a classifier in order to be countable. What is the function of the count-classifiers? If the semantics of a noun involve a partitioning into natural units (i.e., these units do not have to be created), why do we need a separate class of lexical items to name these units as soon as we start counting?

The grammatical way to say 'one big dog' is yi zhi da gou 'one cL big dog', with $d a$ 'big' immediately preceding 
Doetjes (1996) makes an interesting and plausible suggestion in this regard: namely, that in order for count nouns to be able to be counted, the semantic partitioning of what they denote must be (made) syntactically visible. More precisely, numerals require the presence of a syntactic marker of countability. Doetjes argues that in some languages (e.g., English), number morphology is the grammatical marker, whereas in languages that lack number morphology (e.g., Chinese), the grammatical marker is the (count) classifier. On this view, count-classifiers and number morphology both indicate the presence of countable units (see Doetjes 1997:chap. 7 for details). ${ }^{9}$

A connection between number and the count-classifiers is also suggested by Peyraube (1998: 54). He speculates that the development of count-classifiers "might be due to the loss of an infix '-r' which could have be[en] a plurality marker in archaic Chinese." "10 We return to the connection between classifiers and number in section 4 .

In sum, the fact that all nouns require a classifier does not mean that all nouns are mass nouns. Just like English, Chinese languages make a distinction between nouns that are inherently partitioned into countable units (i.e., count) and those that are not (i.e., mass). Both types of language need grammatical markers of countability. English-type languages use number morphology; Chinese-type languages use count-classifiers.

We would like to emphasize the "individualizing function" (Croft 1994:162) of countclassifiers, which enables one to "extract ... distinguished, that is, discrete occurrences," as Iljic (1994:104) puts it. Paris (1981:69) calls the count-classifier "une marque d'individuation, de singularisation" ('a mark of individuation, of singularization'). This brings us back to the terminology used by Longobardi (1994) to describe a function of D (quoted above). Like D, the countclassifier may be said to have a singularizing function: the count-classifier identifies singular units; it picks out one instance of what is denoted by $\mathrm{N}$.

The remaining question regarding the classifier system and Chinese count nouns concerns the consequence of the lack of number/plural morphology in Chinese. We will return to this question in section 2.2.3, where we discuss Chierchia's $(1995,1998)$ proposal regarding the semantic representation of mass nouns.

2.2.2 What Is a Bare Noun? As discussed in section 2.1, bare nouns in Germanic and Romance languages can be defined as nouns without an overt determiner (i.e., [DP [D e] NP]). Bare nouns in Chinese appear to differ with respect to the presence of classifiers. We follow Tang (1990) in assuming that classifiers head their own projection. We suggest that a bare noun in Chinese is at least a $\mathrm{Cl}$ (assifier)P, as shown in (16).

\footnotetext{
${ }^{9}$ A reviewer points out that Doetjes's analysis runs into problems with languages like Turkish, which has number morphology but does not have number agreement when numerals occur (i.e., uc kiz 'three girls', *uc kizlar). Note however that, typologically speaking, Turkish does belong to the type of languages that have number morphology (and therefore is not a classifier-type language like Chinese). Whether or not number agreement takes place may be a question of how number is represented syntactically. (See also Frank 1994, Ritter 1991.)

${ }^{10}$ Universally, there is a tendency for languages without grammatical number to have classifiers (see Greenberg 1963). Ikoro (1994) sketches the development of the Nigerian Cross River language Kana, which lost its number morphology and developed a classifier system, in contrast to related neighboring languages, which kept their number morphology and did not develop a classifier system.
} 
(16)

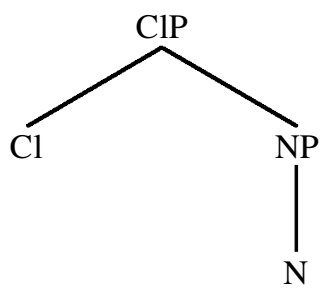

In other words, the bare nouns in examples (1)-(4) have more structure than just NP. For example, if we follow the spirit of Longobardi 1994, indefinite bare nouns can be treated as a CIP with an empty $\mathrm{Cl}^{0}$. This analysis predicts that indefinite bare nouns in Chinese, just like their Italian counterparts, are restricted in terms of distribution-exactly correct, since they are restricted to lexically governed positions. (We will discuss this further in section 3.2.)

A question that naturally arises here concerns the function of classifiers in the overall noun phrase structure. As we noted above, classifiers have an individualizing and singularizing function, just like D. We also mentioned that $\mathrm{D}$ is often assumed to mediate between the description provided by the NP and whatever specific entity in the real world the description is applied to, and we linked this function of $\mathrm{D}$ to the individualizing-singularizing function determiners are also said to have. The underlying assumption is that there is a division of labor between NP, which describes, and D, which refers. This seems to be a general characteristic of language; for example, the same kind of division of labor exists in the verbal domain between the describing VP and the referring, deictic T, which links the event described in the VP to a particular event associated with a particular point on the time axis. ${ }^{11}$ We would like to say, then, that this division of labor is a property of Universal Grammar: some entities describe, whereas other entities perform the deictic discourse function of linking the description to some particular object or event in the real world. In languages with articles/determiners, the deictic function in the nominal phrase is taken care of by the article/determiner. However, this should not lead one to conclude that if a language has no articles/determiners, no element performs the deictic function. If the describing/referring dichotomy is indeed part of Universal Grammar, then if a language has no articles/determiners, some other element in the language must perform the deictic function. We suggest that in Chinese $\mathrm{Cl}^{0}$ performs some of the functions performed by $\mathrm{D}^{0}$, including the deictic function. In subsequent sections we will develop several arguments to this effect. First, however, we briefly discuss Chierchia's $(1995,1998)$ proposal regarding mass and count nouns, on which our analysis of bare nouns will draw.

\subsubsection{Chierchia on Mass Nouns and Category-Type Mappings Chierchia (1995, 1998) makes} two sets of proposals that are pertinent to Chinese noun phrases. The first is a general proposal regarding the semantics of mass nouns; the second concerns Chinese nouns in particular.

\footnotetext{
${ }^{11}$ This is close to John L. Austin's conception of statements. In particular, the "demonstrative conventions" may be comparable to what we here call the "referring function." See Barwise and Etchemendy 1986 for a detailed discussion of the demonstrative conventions and Austin's Truth-Schema.
} 
First, Chierchia proposes the Inherent Plural Hypothesis to account for mass noun properties. In particular, he assumes that in mass nouns the singular/plural distinction is neutralized. Although plural nouns and mass nouns have much in common, they differ in that the extension of mass nouns involves both the individual atoms and their pluralities. He states (1995:2) that "for each mass noun there are minimal objects of that kind, just like for count nouns, even if the size of these minimal parts may be vague" (and in some cases, as with liquids, the minimal parts may not be "readily accessible to our perceptual system"; 1995:36) (see also Doetjes 1996, 1997). According to Chierchia, the mass noun domain is a complete, atomic, join semilattice and the extension of a mass noun is a sublattice of the domain. The extension of a noun like furniture, for example, is represented as in (17) (from Chierchia 1995:18).

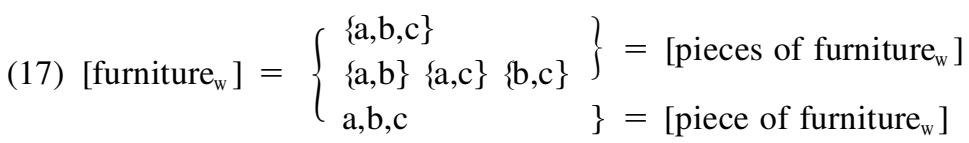
In other words, the extension of the noun furniture encompasses both pluralities and singularities.

This hypothesis contrasts with claims by Bunt (1985) and Landman (1989, 1991), who maintain that mass nouns correspond to structures that do not have minimal parts. The different viewpoints can be summarized as follows. There are two types of mass nouns: nouns like furniture, which refer to entities whose minimal parts can be distinguished by the naked eye, and nouns like water, for which this is not the case. Traditionally, all mass nouns have been treated like water; Chierchia proposes to treat all mass nouns like furniture.

Chierchia's second set of proposals comes down to the claim that Chinese nouns map to the type of entities, $\langle\mathrm{e}\rangle$. In this respect, Chinese nouns differ from nouns in languages like English and Italian. For Chierchia, English represents languages whose nouns can freely alternate between arguments and predicates, and Italian represents languages whose nouns are mapped to predicates only. For Chinese, Chierchia's proposal has two effects. First, nouns do not need to be typeshifted if they occur as arguments. Second, all nouns in Chinese have a mass denotation (again, for details, see Chierchia 1998).

Chierchia's proposal regarding Chinese noun mapping is quite attractive in that it accounts for several Chinese noun phrase features discussed above: (a) bare nouns can freely occur as arguments, (b) there is a generalized classifier system, and (c) there is no plural marking.

However, there are three crucial aspects of Chinese noun phrases that are problematic for Chierchia's proposal. First, recall that indefinite bare nouns cannot appear in preverbal position. This shows that it is not the case that bare nouns can freely occur as arguments. There are restrictions on indefinite bare nouns that must be accounted for. Second, we argued above that Chinese does make a count/mass distinction. Although grammatically the count/mass distinction is not visible at the noun level (i.e., Chinese nouns bear no plural marking, and classifiers are used for all nouns), it is reflected at the classifier level. Third, Chinese bare nouns can be interpreted as both singular and plural. This is problematic for a hypothesis that states that Chinese nouns necessarily have mass extensions/kind denotations.

Consider now the lack of plural/number morphology in Chinese. Absence of plural/number 
morphology entails that a bare count noun in Chinese does not make a distinction between singular and plural. In other words, the singular/plural distinction is neutralized. But this is exactly, in Chierchia's view, a crucial feature of mass nouns. A paradox thus ensues: Chinese makes a count/mass distinction, but its count nouns appear to have the semantic properties that Chierchia attributes to mass nouns.

This paradox can be resolved if we adopt the classification of nouns proposed by Doetjes (1997): singular nouns, plural nouns, count mass nouns (nouns like furniture, whose semantic structure encompasses both individuals and corresponding pluralities), and mass mass nouns (nouns like water, whose semantic structure lacks individuals). The properties Chierchia proposes for mass nouns apply to the class of nouns Doetjes calls count mass nouns.

Now, recall Doetjes's (1996) proposal that number morphology makes the semantic partitioning of count nouns syntactically visible. Thus, in a language without number morphology, the semantic partitioning of count nouns is not made visible (except by using classifiers); in other words, count nouns, although being count nouns semantically, appear to be mass nouns syntactically.

With this hypothesis, it is possible to maintain both that Chinese makes the count/mass distinction and that count nouns in Chinese differ from count nouns in languages like English because Chinese lacks number morphology. Chinese has count nouns and mass nouns: in Doetjes's terminology the former are count mass nouns and the latter are mass mass nouns.

In short, we propose that Chinese nouns are just like nouns in English in terms of mapping (i.e., as predicates, or, in Chierchia's (1998) terms, as individuals or predicates). The difference between the two languages in the count noun domain lies in the fact that Chinese lacks number morphology (and articles, as discussed later).

From now on we assume this characterization of Chinese count nouns: they are count mass nouns (count nouns with no number morphology). We will discuss more evidence for, and properties of, these nouns in subsequent sections. We return to the count/mass distinction when we discuss the consequences of our investigations in section 5 .

\section{The Distribution and Interpretation of Bare Nouns and $[\mathrm{Cl}+\mathrm{N}]$ Phrases}

In this section we propose an account of the distribution and interpretation of bare nouns and $[\mathrm{Cl}+\mathrm{N}]$ phrases in Mandarin and Cantonese. First, we consider the definite interpretation of noun phrases.

\subsection{Definite Noun Phrases}

3.1.1 Definite [Cl+N] Phrases In Cantonese, as (4) and (6) illustrate, definite noun phrases are $[\mathrm{Cl}+\mathrm{N}]$ phrases. Furthermore, definite $[\mathrm{Cl}+\mathrm{N}]$ phrases are not restricted to postverbal positions. These phrases are thus quite similar to English definite DPs such as the man. This is not surprising since, as noted in section 2.2.1, classifiers have a singularizing function, just like D. In other words, if we maintain that Chinese nouns are predicates, classifiers are like Ds in that (a) they are type-shifters, changing predicates into arguments, and (b) they yield the definite 
interpretation (comparable to an iota operator “' $l$ '”) (see also Chierchia's (1998) treatment of English).

Definite $[\mathrm{Cl}+\mathrm{N}]$ phrases in Cantonese nonetheless differ from definite DPs in English in one crucial respect. In English a definite DP is a singular DP if the noun is singular and plural if the noun is plural (e.g., the student vs. the students). Nouns in Chinese languages do not have number and thus have no singular/plural distinction. However, since classifiers are singularizers, $[\mathrm{Cl}+\mathrm{N}]$ phrases are generally singular; the classifier picks out a single instance from the count mass domain. To indicate plurality, a special classifier, di, is used, as shown in (18), in contrast with (19) (taken from Matthews and Yip 1994:89). ${ }^{12}$

(18) a. Di ce zo-zyu go ceot-hau.

CL car block-CONT CL exit

'The cars are blocking the exit.'

b. Di leotsi jiu hou lek sin dak.

CL lawyer need very smart only-okay

'The lawyers had better be very smart.'

(19) a. Gaa ce zo-zyu go ceot-hau.

CL car block-CONT CL exit

'The car is blocking the exit.'

b. Go leotsi jiu hou lek sin dak.

CL lawyer need very smart only-okay

'The lawyer had better be very smart.'

$D i$ thus picks out multiple instances from the domain. The fact that plurality rests upon classifiers provides further support for Doetjes's proposal regarding the function of classifiers (the connection with number morphology).

3.1.2 Definite Bare Nouns Now consider definite noun phrases in Mandarin. As (2) illustrates, definite noun phrases in Mandarin are bare nouns instead of $[\mathrm{Cl}+\mathrm{N}]$ phrases. This naturally leads to questions such as (a) are definite bare nouns in Mandarin NPs or ClPs? (b) how does the definite interpretation arise? and (c) why are definite $[\mathrm{Cl}+\mathrm{N}]$ phrases not possible in Mandarin?

As (1) and (2) illustrate, definite bare nouns in Mandarin differ from their indefinite counterparts in that they can appear in both preverbal and postverbal positions. In line with what we have suggested for indefinite bare nouns, we assume that definite bare nouns are not just NPs, but CIPs. The fact that definite bare nouns can appear in preverbal position suggests that the head of CIP is not empty. In the spirit of Longobardi 1994 (and Ritter 1989, among other works), we propose that in cases where a bare noun receives a definite interpretation, $\mathrm{N}$ has moved to $\mathrm{Cl}$ (i.e., N-to-Cl movement has taken place): once the $\mathrm{Cl}$ position has been filled, the phrase is no longer limited to occurring in lexically governed positions. scheme.

${ }^{12}$ We have changed the romanization in Matthews and Yip 1994 to conform to the Linguistic Society of Hong Kong 
It should be noted that $\mathrm{N}$-to- $\mathrm{Cl}$ movement is covert, as evidenced by noun phrases containing adjectival/possessive modifiers. Overt N-to-D movement of proper names in Italian results in ordering differences, as shown in (20); by contrast, Mandarin bare nouns follow adjectival modifiers, as shown in (21).

(20) a. È venuto il vecchio Cameresi.

came the older Cameresi

'The older Cameresi came.'

b. È venuto Cameresi vecchio.

came Cameresi older

(same)

(21) Huangrong de gou jintian tebie tinghua.

Huangrong DE dog today very obedient

'Huangrong's dog was very obedient today.'

Consider now how the definite interpretation arises. We follow Chierchia (1998) in assuming that for languages that do not have a definite article, the nonovert 1 operator is available. Chierchia (1998) assumes (following Partee (1987)) that the 1 operator is a type-shifter and that it is equivalent to a definite article. ${ }^{13}$ Chierchia proposes that if a language (such as English; see also section 3.2.2) has a definite article, $l$ is not available (i.e., it is blocked). He considers this to represent the last-resort nature of the type-shifting operation: " $[\mathrm{I}] \mathrm{f}$ there is a determiner D whose meaning is a particular type shifting, then use of that operation as an automatic type-changing functor is blocked" (p. 360). Neither Cantonese nor Mandarin has a definite article. However, both languages have the equivalent of a definite article, namely, classifiers. In Cantonese, classifiers are used for definite noun phrases. That is, Cantonese does not resort to $\mathbf{l}$ for definite interpretation of nouns. However, in Mandarin, definite $[\mathrm{Cl}+\mathrm{N}]$ phrases are not possible. Leaving aside for the moment why $[\mathrm{Cl}+\mathrm{N}]$ is not possible in Mandarin (we will discuss this below), the impossibility of using a classifier in this context allows $\mathrm{l}$ to be used.

We suggest that $\mathrm{N}$-to- $\mathrm{Cl}$ movement is a necessary step for use of the $\mathrm{l}$ operator (either because the 1 operator changes the NP $\langle e, t\rangle$ into an individual $\langle e\rangle$, which cannot stay in an NP and thus must undergo movement, or because the $\mathrm{N}$ must be in $\mathrm{Cl}$ position for the $\mathrm{l}$ operator to function). ${ }^{14}$

$\mathrm{N}$-to-Cl movement in Mandarin, in contrast with classifier insertion in Cantonese, can also explain a clear-cut difference in the definite noun phrases of the two languages: namely, Cantonese definite $[\mathrm{Cl}+\mathrm{N}]$ phrases are necessarily singular (except when the classifier $d i$ is used). In Man-

13 "The 1 -operator ... selects the greatest element from the extension of a predicate and constitutes typically the meaning of a definite article ...' (Chierchia 1998:359).

14 This may be problematic if one assumes, following Chierchia (1998), that the indefinite reading in Italian is due to the type-shifter $\exists$, because there is no N-to-D movement in such cases. In Mandarin and Cantonese, as we will show, indefinite noun phrases in fact have more structure than just CIP. Hence, in these languages it is not the case that the indefinite reading arises from a $\exists$ type-shifter. It should also be noted that given our analysis, Mandarin is similar to Scandinavian languages, which allow common nouns to undergo N-to-D movement (see footnote 5). 
darin, however, no overt classifier is present in definite noun phrases; definite bare nouns can thus be interpreted as singular or plural, as shown in (2b).

3.1.3 Proper Names Before we turn to indefinite noun phrases, let us take a brief look at proper names. Examples (22a-b) show that proper names in Mandarin can be preceded by demonstrativenumeral-classifier combinations. (We do not present Cantonese examples here as Cantonese does not differ from Mandarin in this respect.)

(22) a. Guojing shuo ta kandao-le liang-ge Hufei.

Guojing say he see-LE two-CL Hufei

'Guojing said that he saw two Hufei's.'

b. Nei-ge Hufei zhen bu xianghua.

that-CL Hufei truly not decent

'That Hufei is really unreasonable!'

These examples show that proper names in Cantonese and Mandarin are the same as proper names in languages like English in that they can also be generated in $\mathrm{N}$ (with a meaning more akin to kinds). It is certainly the case that proper names do not have to be preceded by classifiers, as shown in $(1 \mathrm{a}-\mathrm{b})$. We assume that in these cases proper names undergo $\mathrm{N}$-to-Cl movement, just like definite bare nouns. In Chierchia 1998, movement of proper names to D position in Italian is attributed to a mismatch between the nature of proper names and the NP category. That is, proper names should be individuals (of type $\langle\mathrm{e}\rangle$ ) and they must move out of an NP category (of type $\langle\mathrm{e}, \mathrm{t}\rangle$ ) (see Longobardi 1994 for a similar proposal).

We would like to point out that "definite" bare nouns in Mandarin can also yield a proper name interpretation, as shown in (23).

(23) a. Linju bu lai le.

neighbor not come SFP

'Neighbor/The neighbor/Neighbors won't come any more.'

b. Wo zuotian peng-shang-le laoshi.

I yesterday bump-up-LE teacher

'Yesterday, I bumped into Teacher/the (my/our) teacher/teachers.'

In the translation of these sentences, we have provided all possible interpretations for the definite noun phrases. The default interpretation of the definite noun phrases here is that they are singular: one neighbor, one teacher. Nevertheless, the interpretation of these noun phrases comes much closer to that of a proper name (Neighbor, Teacher) than to that of a noun-with-a-definite-article in English or to that of a noun-with-a-classifier in Cantonese. In other words, some common nouns can also "refer rigidly to individuals" (Kripke 1972). In such cases they can undergo Nto-Cl movement without the 1 operator (see also Longobardi 1996 for Italian examples of common nouns behaving like proper names).

We would like to point out that although Cantonese bare nouns cannot be used as definites, proper names do surface without a classifier. This should not be surprising since the movement of proper names is driven by the nature of proper names instead of the presence of the 1 operator. 
Thus, syu 'book' can never be interpreted as 'the book(s)', but a proper name like Wufei can surface "bare." Interestingly, in Cantonese, common nouns denoting people, like sin-saang 'teacher' and yau-caai 'postman', can be used without a classifier to denote a definite individual, in which case they have the proper name interpretation, like the Mandarin examples above. In contrast, when the classifier is present, the proper name interpretation disappears. The following two sentences illustrate this clearly:

(24) a. Sin-saang mou lei. teacher not-have come 'Teacher didn't come.'

b. Go sin-saang mou lei. CL teacher not-have come 'The teacher didn't come.'

In other words, in Cantonese, common nouns can also undergo N-to-Cl movement provided that the common noun is interpreted (and therefore treated) like a proper name. When a classifier is present, this is not possible. We attribute this to the individualization function of classifiers. The $[\mathrm{Cl}+\mathrm{N}]$ phrase with an overt classifier yields an interpretation in which the classifier picks out a particular instance of the kind denoted by the common noun. This yields the definite interpretation and not a proper name interpretation.

\subsection{Indefinite Noun Phrases}

3.2.1 Indefinite $[\mathrm{Cl}+\mathrm{N}]$ Phrases Consider first the distribution of indefinite $[\mathrm{Cl}+\mathrm{N}]$ phrases in Cantonese ((25) is taken from Matthews and Pacioni 1996:(23); (19) is repeated here as (26)).

(25) a. Keoi seung maai gaa ce.

he want buy CL car

'He wants to buy a car.'

b. Keoi maai-zo gaa ce.

he sell-zo CL car

'He sold the car.'

(26) a. Gaa ce zo-zyu go ceot-hau.

CL car block-CONT CL exit

'The car is blocking the exit.' not: 'A car is blocking the exit.'

b. Go leotsi jiu hou lek sin dak.

CL lawyer need very smart only-okay

'The lawyer had better be very smart.' not: 'A lawyer had better be very smart.'

When $[\mathrm{Cl}+\mathrm{N}]$ phrases appear postverbally, as in (25), both definite and indefinite interpretations are possible (the verb maai 'to buy' differs from the verb maai 'to sell' in tone). Note that in (25b) the predicate maai-zo 'sold' could in principle facilitate either a specific indefinite reading 
or a definite reading (see footnote 1). The fact that gaa ce 'CL car' can be interpreted as definite but not indefinite in $(25 \mathrm{~b})$ suggests that when $[\mathrm{Cl}+\mathrm{N}]$ phrases are interpreted as indefinite, they must be nonspecific as well (we will discuss this further shortly below). In contrast, when [Cl $+\mathrm{N}]$ phrases appear preverbally, as in (26), only the definite reading is possible. This is reminiscent of the distribution of indefinite bare nouns (i.e., only postverbal position is possible).

Mandarin $[\mathrm{Cl}+\mathrm{N}]$ phrases display the same distribution, as shown by the contrast between (27) and (28). Note that since definite noun phrases in Mandarin cannot be $[\mathrm{Cl}+\mathrm{N}]$ phrases, (28) is ungrammatical (in contrast with Cantonese $[\mathrm{Cl}+\mathrm{N}]$ phrases, which can be interpreted as definite, as in (26)).

(27) a. Wo xiang kan ben shu.

I would.like read CL book

'I would like to read a book.'

b. Men-qian you ge ren.

door-front have CL people

'There is someone outside the door.'

(28) *Ben shu bu hao.

CL book not good

'The/A book is not good.'

As noted earlier, it is not generally believed that $[\mathrm{Cl}+\mathrm{N}]$ combinations in Mandarin can appear without a numeral or a demonstrative (but see Paris 1981). Sentences like (27a-b) are viewed as cases of phonological reduction of the numeral $y i$ 'one'. On this view, ben shu 'CL book' in (27a) stands for $y i$-ben shu 'one-CL book' in which the numeral gets suppressed in (fast) speech only.

We have reasons to think that this view is wrong: Mandarin (or Cantonese) $[\mathrm{Cl}+\mathrm{N}]$ phrases are not simply phonological reductions of $[y i-\mathrm{Cl}+\mathrm{N}]$ 'one $\mathrm{Cl}+\mathrm{N}$ '. The main reason is that $[\mathrm{Cl}+\mathrm{N}]$ phrases and $[y i-\mathrm{Cl}+\mathrm{N}]$ phrases have a different distribution. In particular, as (25) shows, indefinite $[\mathrm{Cl}+\mathrm{N}]$ phrases in Cantonese can be interpreted as indefinite nonspecific only. On the other hand, $[y i-\mathrm{Cl}+\mathrm{N}]$ phrases can be interpreted as specific and nonspecific indefinites. Thus, in contexts where only an indefinite specific interpretation is possible, $[\mathrm{Cl}+\mathrm{N}]$ phrases should not be able to surface. We present two contexts showing that this prediction is borne out.

The first context involves bounded predicates. Sybesma (1992:176-178) argues that with predicates that are bounded for reasons independent of the object, a strong reading is forced upon the object: a bare noun is interpreted as definite, an indefinite NP as specific. Comparing (29) and (30), we find that a $[\mathrm{Cl}+\mathrm{N}]$ phrase cannot occur as the object of one of these bounded predicates (however fast the sentence is pronounced), whereas $[y i-\mathrm{Cl}+\mathrm{N}]$ phrases can, with a specific reading. There is no phonological reason why $y i$ 'one' could not be suppressed in (30).

(29) a. Wo chi-wan-le yi-kuai binggan.

I eat-finish-LE one-CL cookie

'I finished a cookie.' 
b. Wo he-wan-le yi-wan tang.

I drink-finish-LE one-bowl soup

'I finished a bowl of soup.'

(30) a. *Wo chi-wan-le kuai binggan.

I eat-finish-LE CL cookie

b. *Wo he-wan-le wan tang.

I drink-finish-LE bowl soup

The examples in (30) show that $[\mathrm{Cl}+\mathrm{N}]$ phrases in Mandarin must be nonspecific indefinites. The ba-construction (31) provides a similar context of boundedness, and the same pattern emerges: $[y i-\mathrm{Cl}+\mathrm{N}]$ is acceptable, $[\mathrm{Cl}+\mathrm{N}]$ is not. Once again, there is no reason why $y i$ 'one' could not be suppressed here.

(31) a. Wo ba yi-wan tang he-wan-le.

I BA one-bowl soup drink-finish-LE

'I finished a (particular) bowl of soup.'

b. *Wo ba wan tang he-wan-le.

I B A bowl soup drink-finish-LE

The second context involves sentences with secondary predication. Huang (1987) shows (see also Tsai 1994) that the object NP in these sentences (i.e., the subject of the secondary predicate) must be indefinite and specific. Furthermore, Huang shows that a bare noun cannot appear in such sentences, indicating that bare nouns cannot be interpreted as specific indefinites. The sentences in (32) and (33) illustrate the contrast. (EXP = experiential)

(32) a. Wo jiao-guo yi-ge xuesheng hen congming.

I teach-EXP one-CL student very intelligent

'I once taught a student who was very intelligent.'

b. Ta xie-guo yi-ben shu hen you-yisi.

he write-EXP one-CL book very interesting

'He once wrote a book which was very interesting.'

(33) a. *Wo jiao-guo xuesheng hen congming.

I teach-EXP student very intelligent

b. *Ta xie-guo shu hen you-yisi.

he write-EXP book very interesting

As (34) shows, when $[\mathrm{Cl}+\mathrm{N}]$ phrases are substituted for $[y i-\mathrm{Cl}+\mathrm{N}]$ phrases in (32), the result is also ungrammatical. $[\mathrm{Cl}+\mathrm{N}]$ phrases are thus like bare nouns in that they cannot appear as the object in sentences involving secondary predicates.

(34) a. *Wo jiao-guo ge xuesheng hen congming.

I teach-EXP CL student very intelligent

b. *Ta xie-guo ben shu hen you-yisi.

he write-EXP CL book very interesting 
The contrast between (34) and (32) shows further that $[\mathrm{Cl}+\mathrm{N}]$ phrases cannot simply be considered the reduced form of $[y i-\mathrm{Cl}+\mathrm{N}]$ phrases. In addition, indefinite $[\mathrm{Cl}+\mathrm{N}]$ phrases cannot be interpreted as specific.

3.2.2 The Indefinite $[\mathrm{Cl}+\mathrm{N}]$ and Why Cantonese and Mandarin Differ From the above data on indefinite noun phrases in Mandarin and Cantonese, it is clear that indefinite bare nouns and indefinite $[\mathrm{Cl}+\mathrm{N}]$ phrases are similar in interpretation and distribution: both are interpreted as nonspecific indefinites, and both are restricted in distribution (postverbal/governed positions). What accounts for this similarity? In particular, is there a structure that can account for the two indefinite noun phrase types while taking the restriction in interpretation into consideration as well?

Given our earlier hypothesis regarding indefinite bare nouns, the null hypothesis for the indefinite $[\mathrm{Cl}+\mathrm{N}]$ phrases is that they too contain an empty element that must be lexically governed. The obvious question is what that empty category might be. An obvious choice is Numeral. That is, an indefinite $[\mathrm{Cl}+\mathrm{N}]$ is in fact a NumeralP, with an empty Numeral head. Tang (1990) suggests that a NumeralP can occur between DP and ClP, as shown in (35). ${ }^{15}$ (For Tang (but not for us), demonstratives are Ds. Thus, (35) can be a structural representation of (36).)

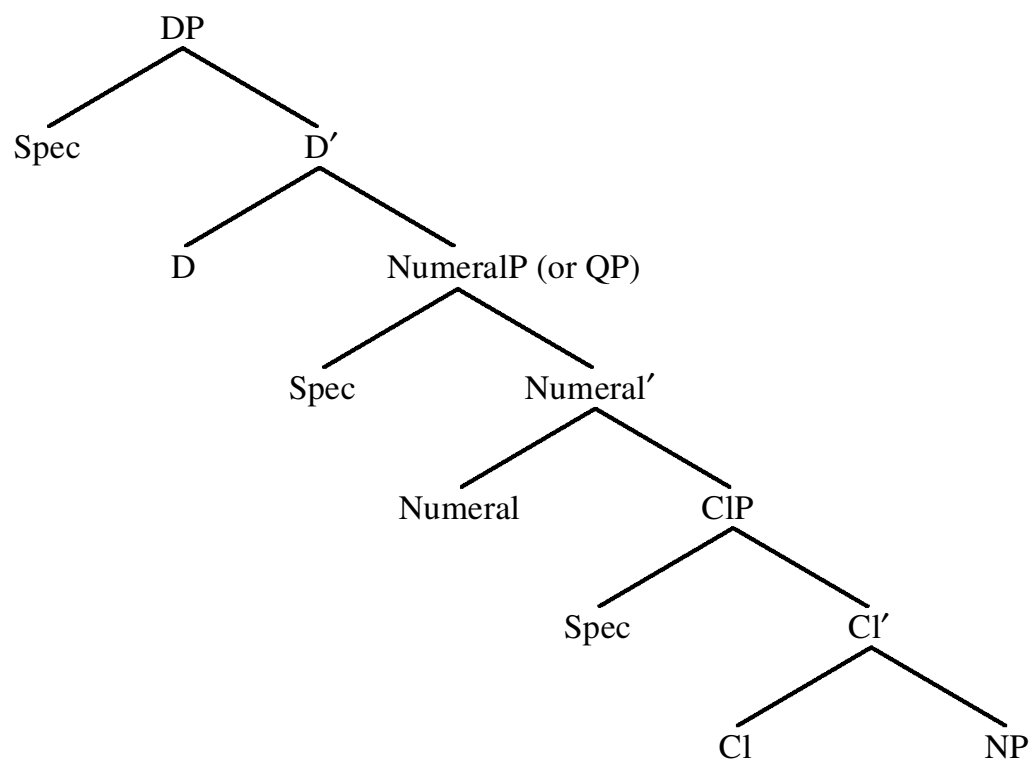

(36) zhe san ben shu DEM three CL book 'these three books'

${ }^{15}$ Pan (1990) proposes a structure similar to (35) for Chinese noun phrases. 
If it is true that indefinite $[\mathrm{Cl}+\mathrm{N}]$ involves an empty Numeral head, there are two different structures for surface $[\mathrm{Cl}+\mathrm{N}]$ strings: (a) $[\mathrm{Cl}+\mathrm{N}]$ phrases that are ClPs, which yield a definite reading, and (b) $[\mathrm{Cl}+\mathrm{N}]$ phrases that are NumeralPs with an empty Numeral head, which yield an indefinite reading and have a restricted distribution.

Some questions arise given this account. In particular, (a) why can't Mandarin $[\mathrm{Cl}+\mathrm{N}]$ phrases yield a definite reading? and (b) do indefinite bare nouns differ from indefinite $[\mathrm{Cl}+\mathrm{N}]$ phrases in that the former are CIPs and the latter NumeralPs? The following chart will help in answering these questions:

(37) The interpretation of the different types of nouns

\begin{tabular}{llllll} 
& \multicolumn{3}{c}{ Mandarin } & & \multicolumn{2}{c}{ Cantonese } \\
\cline { 2 - 3 } \cline { 5 - 6 } & Indef & Def & & Indef & Def \\
\hline Bare N & + & + & & + & - \\
$\mathrm{C} 1+\mathrm{N}$ & + & - & & + & + \\
$\mathrm{Num}+\mathrm{Cl}+\mathrm{N}$ & + & - & & + & - \\
\hline
\end{tabular}

(37) shows very clearly that in both languages, noun phrases with overt numerals can only be interpreted as indefinite. That is, overt numerals in a noun phrase consistently lead to an indefinite interpretation. In contrast, both bare nouns and $[\mathrm{Cl}+\mathrm{N}]$ phrases vary in interpretation (with some language-particular differences).

We suggested above that indefinite $[\mathrm{Cl}+\mathrm{N}]$ phrases are in fact NumeralPs with an empty Numeral head. Combining this with the claim that noun phrases with overt numerals necessarily yield an indefinite interpretation, owing to the quantificational nature $(\exists)$ of numerals, we can make the following generalization:

(38) The indefinite interpretation of nominals in Chinese is linked to the presence of a NumeralP (the head of which may be overt or nonovert).

Superficially, a noun phrase such as yi-ge xuesheng 'one-CL student' is interpreted like one student in English. However, when classifiers are considered to be singularizers, yi-ge xuesheng is more adequately paraphrased as 'one instance of the (kind) student'.

A question arises regarding the indefinite interpretation of bare nouns. Are they also NumeralPs? They must be, in view of (38). In other words, they have not only an empty $\mathrm{Cl}$ head, as we have argued, but an empty Numeral head as well.

Consider again the interpretation of definite bare noun phrases. In our proposal, definite bare noun phrases are CIPs, and their definiteness stems from the 1 operator, which can be considered to be like a definite article. The numeral apparently has the effect of undoing the definiteness, just as with $[\mathrm{Cl}+\mathrm{N}]$ phrases preceded by a numeral. An indefinite bare noun is thus interpreted as ' $x$ instance of the noun'. This means that both indefinite bare nouns and indefinite $[\mathrm{Cl}+\mathrm{N}]$ phrases are NumeralPs, the former having an empty Numeral head and an empty $\mathrm{Cl}$ head and the latter only an empty Numeral head. This entails that they are essentially interpreted the same 
way, a result supported by the restriction of the nonspecific reading of bare indefinites and indefinite $[\mathrm{Cl}+\mathrm{N}]$ phrases (as shown in (33) and (34)).

Under this account, then, surface strings of the form $[\mathrm{Cl}+\mathrm{N}]$ have two different structural representations: $[\mathrm{Cl}+\mathrm{N}]$ with an indefinite reading is a NumeralP, as in (39), and $[\mathrm{Cl}+\mathrm{N}]$ with a definite reading is a $\mathrm{ClP}$, as in (40). ${ }^{16}$

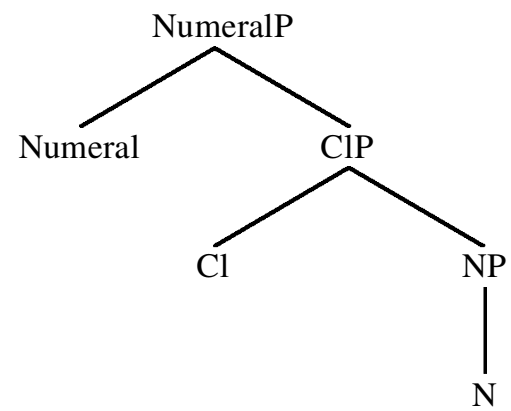

(40)

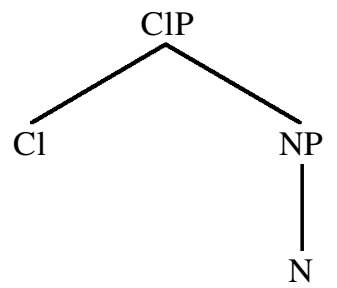

We propose that the same applies to bare nouns: a surface string in the form of a bare noun can have either the structure in (39) or the structure in (40). Indefinite bare nouns have the structure in (39) (with the Numeral for indefinite interpretation); definite bare nouns have the structure in (40). In other words, the structures in (39) and (40) are in fact the structures for indefinite NPs (surface: Num-Cl-N, Cl-N, N) and definite NPs (surface: $\mathrm{Cl}-\mathrm{N}, \mathrm{N}$ ), respectively.

Now consider the fact, shown in (37), that bare nouns in Cantonese, and $[\mathrm{Cl}+\mathrm{N}]$ phrases in Mandarin, cannot be interpreted as definite. As we have argued, in principle, both languages have the structures in (39) and (40) for indefinite and definite NPs. Thus, the differences must be attributed to language-particular restrictions. What could these restrictions be?

Let us first consider the fact that Mandarin $[\mathrm{Cl}+\mathrm{N}]$ phrases cannot have a definite interpretation. It is a consequence of our analysis that Mandarin $[\mathrm{Cl}+\mathrm{N}]$ phrases cannot have the structure in (40). Since the difference between (39) and (40) is that the latter lacks the Numeral projection, the Mandarin restriction suggests that in Mandarin, for reasons we do not understand, overt classifiers simply cannot appear without a Numeral (even though the Numeral may be nonovert). We state this restriction as follows, leaving open the question of how it can be explained:

\footnotetext{
${ }^{16}$ It should be noted that nothing can intervene between Numeral and $\mathrm{Cl}$ (aside from the small set of adjectives exemplified in (14)). This may be due to some obligatory cliticization of $\mathrm{Cl}$ to Numeral (see Tang 1990). We leave this question open.
} 
(41) In Mandarin, overt classifiers are always accompanied by a Numeral. The Numeral can be overt or nonovert. ${ }^{17}$

In other words, in Mandarin, whenever there is an overt classifier, it must occur in the structure in (39). Cantonese lacks such a restriction on the occurrence of overt classifiers: in this language the occurrence of a classifier does not automatically imply the presence of a Numeral. Hence, unlike what we see in Mandarin, Cantonese nouns involving a classifier are not necessarily indefinite. This explains why $[\mathrm{Cl}+\mathrm{N}]$ phrases in Mandarin cannot be interpreted as definite.

Next let us consider why bare nouns in Cantonese cannot be interpreted as definite. Recall that to express definiteness, Cantonese uses $[\mathrm{Cl}+\mathrm{N}]$ phrases, whereas in Mandarin the bare noun is moved to $\mathrm{Cl}$ position (with the $\mathrm{l}$ operator present). In other words, either the $\mathrm{Cl}$ position is filled by a classifier (Cantonese), or the 1 operator is used, followed by N-to-Cl movement (Mandarin). The question is why Cantonese and Mandarin differ. We would like to suggest that given a choice between insertion of a lexical item and movement, a language always chooses insertion. ${ }^{18}$ This is reminiscent of Chierchia's treatment of definite noun phrases in English. Chierchia suggests that "[t]here is a principle that seems to be fundamental for the architecture of grammar which says, roughly, 'Language particular choices win over universal tendencies' ... or 'Don't do covertly what you can do overtly',' (1998:360). In other words, Cantonese takes the default option. Mandarin, on the other hand, cannot take that option because of the language-particular constraint (41) barring overt classifiers from occurring without a numeral.

Finally, we turn briefly to specificity. We noted earlier that indefinite nouns with an overt numeral can be interpreted as both specific and nonspecific, whereas indefinite bare nouns and $[\mathrm{Cl}+\mathrm{N}]$ phrases can be interpreted only as nonspecific. This might be linked to the empty Numeral: an empty Numeral leads to a nonspecific interpretation. One possible explanation for the difference between an empty Numeral and an overt Numeral is that the latter is a full-fledged quantifier and thus can undergo Quantifier Raising (QR), yielding a specific reading. In contrast, an empty Numeral lacks the QR option. Instead, it relies on the presence of Existential Closure to supply the existential quantification, yielding a narrow scope nonspecific reading (see Diesing 1992).

3.2.3 Further Support Part of the analysis presented above depends on the link between the interpretation of certain nominals and the assumption that an empty category is involved in regulating their distribution. Given the analysis and data we have presented so far, it is possible to come up with an alternative analysis based on a restricted application of Existential Closure (Diesing 1992, Tsai 1994). This alternative analysis can be briefly summarized as follows: a bare noun or a $[\mathrm{Cl}+\mathrm{N}]$ phrase can be interpreted as a variable bound by Existential Closure only if

\footnotetext{
${ }^{17}$ One piece of evidence showing that classifiers in Mandarin must cooccur with a numeral is provided by demonstratives. In Mandarin the demonstratives zhe/na 'this/that' have the variants zhei/nei. These variants have been analyzed as the demonstrative form plus the numeral $y i$ 'one' (e.g., zhei $=z h e+y i$ ). However, these variants can be used only when a classifier is present, not when the demonstrative appears alone: zhei ben shu 'this CL book' versus $z h e / * z h e i$ bu hao 'this (is) not good'. In contrast, in Cantonese the demonstratives li/go 'this/that' do not have variants and can appear alone or with classifiers.

18 This does not fall under "economy of derivation" (Chomsky 1995) since we are dealing with different numerations.
} 
it is within VP, since the domain covered by Existential Closure is VP (or the predicate domain according to Tsai 1994). Crucially, in this approach there would be no need for a lexical government requirement and therefore no empty Numeral head. Note that this analysis would also account for the fact that all indefinite noun phrases in Mandarin and Cantonese are barred from preverbal position. In other words, indefinite noun phrases with overt numerals are predicted to have the same distribution as bare nouns and $[\mathrm{Cl}+\mathrm{N}]$ phrases.

However, there is evidence showing the opposite. Consider sentences with the lian . . dou construction in Mandarin. The lian ... dou construction can be roughly interpreted to have a focus interpretation like 'even' (see Tsai 1994 and Shyu 1996 for detailed discussion of this construction). The focused noun phrase that appears between lian and dou can be indefinite or definite, as shown in (42).

(42) a. Lian yi-ge xuesheng dou mei lai.

even one-CL student all not-have come

'Not even a student showed up.'

b. Lian Hufei dou mei lai.

even Hufei all not-have come

'Not even Hufei showed up.'

In lian . . dou constructions, lian is optional. Thus, the sentences in (43) where lian is absent, are interpreted like those in (42).

(43) a. Yi-ge xuesheng dou mei lai.

one-CL student all not-have come

'Not even a student showed up.'

b. Hufei dou mei lai.

Hufei all not-have come

'Not even Hufei showed up.'

Note that in (43) the indefinite noun phrase appears in a preverbal position. Leaving aside what provides the quantificational force for the indefinite noun phrase, it is clear that an indefinite noun phrase with an overt numeral can appear preverbally.

Now consider cases involving indefinite $[\mathrm{Cl}+\mathrm{N}]$ phrases (we will not consider bare nouns or Cantonese $[\mathrm{Cl}+\mathrm{N}]$ phrases since they always allow a definite interpretation).

(44) a. Lian ge xuesheng dou mei lai.

even CL student all not-have come

'Not even a student showed up.'

b. *Ge xuesheng dou mei lai.

CL student all not-have come

'Not even a student showed up.'

As (44a) shows, an indefinite $[\mathrm{Cl}+\mathrm{N}]$ phrase can appear between lian and $d o u$ as a focused noun phrase. As (44b) shows, however, in such a case lian cannot be deleted. This contrast follows 
from our analysis of indefinite $[\mathrm{Cl}+\mathrm{N}]$ phrases. In particular, lian is similar to a preposition (i.e., a governor). In (44a) it serves to lexically govern the empty Numeral of the $[\mathrm{Cl}+\mathrm{N}]$ phrase. In contrast, in (44b) the empty Numeral lacks a governor and the sentence is therefore ungrammatical.

The contrast shown here suggests that even if Existential Closure plays a role in the indefinite interpretation of bare nouns and $[\mathrm{Cl}+\mathrm{N}]$ phrases, the restricted domain of application cannot be the whole story. In particular, to account for the restricted distribution of indefinite $[\mathrm{Cl}+\mathrm{N}]$ phrases, it is necessary to appeal to the existence of an empty Numeral.

\subsection{Generic Interpretation}

We showed at the outset that bare nouns can also have a generic/kind interpretation whereas $[\mathrm{Cl}+\mathrm{N}]$ phrases cannot. Furthermore, bare nouns with a kind interpretation are similar to definite bare nouns in that they are not restricted to lexically governed positions. We mentioned that Longobardi (1994) assumes that generics (in English) involve N-to-D movement, just like proper names. Since generics in Cantonese and Mandarin are like proper names in terms of distribution, the null hypothesis is that in these two languages bare nouns with a kind interpretation also undergo $\mathrm{N}$-to-Cl movement. In other words, such bare nouns are treated like proper names and definites. The question that arises is whether it is natural to treat generics as definites and proper names. If so, where does the kind interpretation come from? In this section we discuss the similarity between generics and definites beyond the apparent nonrestricted distribution of these two types of noun phrases.

Consider first the bare nouns in (45) (cf. Krifka 1995:398, ex. (1)).

(45) a. Xiongmao kuai jue-zhong le.

panda soon extinct SFP

'The panda will soon be extinct.'

b. Hufei hen taoyan mao.

Hufei very hate cat

'Hufei hates cats.'

In (45a) and (45b) both bare nouns are kind-referring noun phrases (see Krifka et al. 1995). They do not refer to an ordinary individual or an object. Instead, they denote the kind.

Krifka et al. (1995) consider a subclass of kind-referring noun phrases to be proper names semantically. There are two reasons for this: (a) both kind-referring noun phrases and proper names are definite and referring expressions; and (b) proper names can be used as kind-referring noun phrases, as shown in (46) (Krifka et al.'s (104b), p. 65; it means the same as (47), their (104a)).

(46) Ailuropoda melanoleuca will become extinct soon.

In other words, it is not at all far-fetched to connect kind-denoting nouns with definites and proper names. Although our analysis is based on distributional facts, it has apparent semantic support. Note also that the ability of bare nouns in Mandarin to be interpreted as either generics or definites is no different from the ability of definite noun phrases in English to be interpreted as generics. 
(47) The panda will become extinct soon.

It is well known that certain verbal predicates require a kind-referring noun phrase-for example, a predicate such as be extinct. Depending on the predicate, either the kind-denoting interpretation or the object-denoting interpretation of a noun phrase is brought out.

As for how the kind interpretation arises, we simply assume, following Chierchia (1998), that the "down" function-that is, the $\cap$ operator (the "nominalization"-of-predicates operator) - yields kinds when plural predicates (common nouns) are involved. ${ }^{19}$ Since Chinese common nouns are neutralized in terms of number, the "down" function can always apply, yielding kind interpretation. The movement of bare nouns in such a case is like $\mathrm{N}$-to-Cl movement involving the 1 operator.

A remaining question is why $[\mathrm{Cl}+\mathrm{N}]$ phrases cannot have a kind interpretation. For Mandarin, it is possible to invoke the language-particular restriction in (41) that does not allow $[\mathrm{Cl}+\mathrm{N}]$ to appear without a numeral. So the Mandarin $[\mathrm{Cl}+\mathrm{N}]$ phrase's lack of a definite make-up precludes the possibility of a kind interpretation; and the presence of a Numeral (though nonovert) leads to an indefinite interpretation. In Cantonese the picture is slightly more complicated. Here $[\mathrm{Cl}+\mathrm{N}]$ phrases are allowed to occur without a numeral, and they may be interpreted as definite. Why, then, can such phrases be interpreted only as definites, not as kinds? Note that if singular classifiers (almost all classifiers are singular except the plural classifier $d i$ ) are used, the kind interpretation is not allowed. However, it appears that when the plural classifier di is used, in certain contexts, the kind interpretation is actually possible (see Au Yeung 1997). ${ }^{20}$ Consider the contrast between (48a) and (48b).

(48) a. Siuming seung sik go mou wat ge saigwaa.

Siuming want eat CL no seed MOD watermelon

'Siuming wants to eat a seedless watermelon.'

b. Siuming zungji sik di mou wat ge saigwaa.

Siuming like eat $\mathrm{CL}^{\mathrm{PL}}$ no seed MOD watermelon

'Siuming likes to eat seedless watermelons.'

In (48a), with the singular classifier go, only a nongeneric reading is possible (here, a more natural reading is an indefinite reading). For (48b), the generic reading is possible. We noted earlier that classifiers have an individualization function. This is the case for the singular classifiers. Such a

${ }^{19}$ Chierchia (1998:351) defines the "down" function as follows:

(i) For any property $\mathrm{P}$, and world/situations,

$\cap \mathrm{P}=\lambda \mathrm{s} \iota \mathrm{Ps}$, if $\lambda$ si Ps is in $\mathrm{K}$, else undefined.

where $\mathrm{Ps}$ is the extension of $\mathrm{P}$ in $\mathrm{s}$.

${ }^{20}$ We do not understand why di cannot always yield a generic interpretation. In (i), for example, if saigwaa 'watermelon' appears without being modified by mou wat 'without seeds', the sentence is unacceptable.

(i) *Siuming zungji sik di saigwaa.

Siuming like eat $\mathrm{CL}^{\mathrm{PL}}$ watermelon

'Siuming likes to eat watermelons.' 
classifier is necessarily object-referring; that is, it picks out a particular individual. The plural classifier $d i$ does not pick out a singular individual. Instead, it is supposed to pick out a set of individuals. If it happens to pick out a whole kind, the kind interpretation is possible.

Finally, one may wonder why a noun phrase in Chinese of the form [Numeral-Cl-N], with the numeral 'one', $y i$, cannot be interpreted like the indefinite noun phrase in (49) (Krifka et al. 1995:3, ex. (2b)), which is an indefinite in the scope of a generic operator.

(49) A potato contains vitamin $\mathrm{C}$, amino acids, protein, and thiamine.

Note that although $[y i-\mathrm{Cl}+\mathrm{N}]$ is often translated as ' $\mathrm{a}(\mathrm{n}) \mathrm{N}$ ', it in fact has the interpretation 'one N'.

(50) Fan hou, ta xihuan chou (yi)-gen yan. meal after he like smoke one-cL cigarette

'After a meal, he likes to smoke a cigarette.'

The numeral indicates how many representatives of the kind 'cigarette' are being denoted. And crucially, given the presence of the classifier, the kind-denotation is already "suppressed." In Paris's (1981:84) words: “En construisant une occurrence $a_{j}$ de A, Q Cl bloque l'interprétation générique" ('In constructing an occurrence $\mathrm{a}_{\mathrm{j}}$ of $\mathrm{A}, \mathrm{Q} \mathrm{Cl}$ blocks the generic interpretation').

\subsection{Summary}

To conclude this section, let us summarize some of the main claims and hypotheses. We showed that although Chinese count nouns are count mass nouns (semantically count and syntactically mass), there is a count/mass distinction in Mandarin and Cantonese, the two Chinese languages that we examined. Further, bare nouns in Chinese are not really bare: they must at least be embedded in a projection that performs the deictic discourse function of linking the description provided by the noun or noun phrase to a specific entity in the world.

The assumption that $\mathrm{N}$ is embedded in another phrase enabled us to straightforwardly apply some of the ideas developed by Longobardi (1994) and account for the distribution of indefinite bare nouns and indefinite $[\mathrm{Cl}+\mathrm{N}]$ phrases. Assuming that the head of the projection above NP can be empty and that empty heads must be lexically governed, the fact that indefinite bare nouns and $[\mathrm{Cl}+\mathrm{N}]$ phrases are distributionally restricted to lexically governed positions, and their definite counterparts are not, suggests that the former involve an empty head and the latter do not.

This led to postulating the structures in (39) and (40). The structure in (40) represents definite bare nouns and $[\mathrm{Cl}+\mathrm{N}]$ phrases: the NP is embedded in a ClP, which (among other things) performs the deictic function assumed to be performed by $\mathrm{D}$ in Romance and Germanic languages. We noted that to express definiteness, either the nonovert 1 operator or an overt classifier is used; the former option leads to $\mathrm{N}$-to-Cl movement.

The structure in (39) represents indefinite nouns. This structure contains not only the deictic $\mathrm{ClP}$, but also a NumeralP, which is responsible for the indefiniteness (due to the existential quantificational force associated with numerals). 
The differences between Mandarin and Cantonese can all be traced back to the restriction in (41), namely, in Mandarin, but not in Cantonese, overt classifiers can occur only with a NumeralP, the head of which may or may not be overt. This, we argued, bars Mandarin from filling the $\mathrm{Cl}^{0}$ slot by inserting a classifier, which seems to be the default procedure. Instead, Mandarin must resort to the 1 operator (and thus $\mathrm{N}$-to-Cl movement). This explains why $[\mathrm{Cl}+\mathrm{N}]$ phrases can only be indefinite in Mandarin (the $\mathrm{Cl}$ subsumes the presence of a Numeral and is thus indefinite) but indefinite or definite in Cantonese and why bare nouns can be both definite and indefinite in Mandarin but only indefinite in Cantonese (Cantonese only has N-to-Cl movement with generics and proper names because it lacks the restriction formulated for Mandarin in (41)). Another difference connected to the constraint in Mandarin is that definite nominals are neutral for number when they are bare, whereas $[\mathrm{Cl}+\mathrm{N}]$ phrases are never neutral for number, owing to the presence of the classifier. We furthermore noted that nominals embedded in a NumeralP with an empty head are always nonspecific.

\section{DP, CIP, and Number}

Szabolcsi (1994) distinguishes two Ds/determiners in Hungarian, each with a different function. One is what she calls a "subordinator" (Szabolcsi 1994:218) (basically meaning that it marks the NP as a possible argument); the other has the function of a quantifier/demonstrative. She suggests that although in some languages (e.g., Hungarian) these two functions are performed by two different morphemes, in other languages (e.g., English) they may be conflated and may be borne by one morpheme.

We would like to take this reasoning one step further and say that the superstructure of NP involves a certain number of functions, and these functions may either each be performed by a different lexical item, or be conflated in a number of different combinations. This is not the place to formulate a full theory or inventory all the possible functions and combinations. The deictic function (which we compare to the function of T) and the subordinator function (which Szabolcsi likens to the function of C) will certainly belong to the inventory. The quantifier and demonstrative functions may be on the list as well. Another possible candidate is Number. Surely, Number belongs to the superstructure of the noun (see Ritter 1989), and although it is often assumed to be a separate category, the argument has been made (Delfitto and Schroten 1991) that in French it is expressed, not at the level of $\mathrm{N}$, but, if anywhere, at the level of D. And what about noun classification? Some languages seem to have a special category of classifiers, but, as Croft (1994) points out, insofar as noun classification plays a role in Germanic and Romance languages, it is in the domain of gender, and gender is generally encoded in the determiner system in these languages. In other words, the determiner system of some languages is involved in noun classification too.

What we would like to make clear is that classifiers in Chinese appear to be involved in expressing number. We have already noted Doetjes's (1996) proposal that it is the function of the classifier to make the semantic partitioning of count nouns syntactically visible. We also pointed out that the deictic function of $\mathrm{D}$ and $\mathrm{Cl}$ is in some ways related to their ability to pick out singular instances of whatever is denoted by $\mathrm{N}$. 
The idea that classifiers are involved in grammatical number is not new. Paris (1989:3), for instance, states that the classifiers in Chinese do not really classify; they have more to do with number than with "genre" (for extensive discussion, see Paris 1981). Indeed, the case can be made that in Chinese the classifier is the locus of grammatical number. In section 3.1 we showed that in Cantonese it is very clearly the classifier that determines the interpretation of $[\mathrm{Cl}+\mathrm{N}]$ phrases as singular or plural; and Mandarin too has a classifier for indefinite plurality (xie). For Mandarin, the following example (adapted from Iljic 1994) has been used to show that both the demonstrative and the noun are entirely neutral for number (see also footnote 17):

(51) $\mathrm{Ni}$ zhe xin dei cheng yi-xia ... ta chao-zhong-le/liang-feng dou your this/these letter/s must weigh a-bit it overweight-LE/two-CL all chao-zhong-le.

overweight-LE

'This/These letter(s) of yours must be weighed ... it is/they are both overweight.'

Similarly, a noun can be pluralized by reduplicating the classifier, as illustrated in (52); even though $(52 \mathrm{a}-\mathrm{b})$ involve universal quantification, we may regard it as a type of pluralization (Paris 1981:69).

(52) a. ge-ge xuesheng

CL-CL student

'every student'

b. Tiao-tiao daolu tong Beijing.

CL-CL road connect Peking

'All roads lead to Peking.'

In addition, it has been pointed out that the classifiers in Chinese entertain a very close relationship with the numerals. Croft (1994:151), for instance, states that in classifier systems like that of Chinese, "the numeral and the classifier form one constituent." Tang (1990:403) proposes that the numeral and the classifier form a dual head of CIP (see also footnote 16).

These considerations suggest that ClP in Chinese is involved in the expression of grammatical number.

In this context it is necessary to mention the morpheme men, which is sometimes referred to as a plural suffix ( $\mathrm{Li}$ and Thompson 1981:40). We do not think this designation is correct, and we agree with Iljic (1994), who follows Lü (1947) in arguing that men is instead a collective suffix. It must be pointed out that the distribution of this suffix is very limited, in two ways. First, it occurs primarily on nouns referring to humans and on pronouns, and in rare cases it can be suffixed to proper names, as illustrated in (53a), taken from Iljic 1994:95.

(53) a. ni-men

yOu-MEN

'you (plural)'

b. Xiao Qiang-men

Xiao Qiang-meN

'Xiao Qiang's group' 
c. Haizi-men!

child-MEN

'Children!'

d. *san-ge haizi-men

three-CL child-MEN

Second, the nouns adorned with the suffix can be used only in a very limited number of contexts, partly because of their very limited range of meanings (Iljic 1994). Nouns suffixed with men cannot be used with a numeral, so (53d) is ungrammatical. Iljic points out that nouns suffixed with men cannot be used generically or indefinitely: they "invariably [refer] to a situationally anchored and defined group" (1994:94). In fact, as he argues, the most natural context in which to use nouns suffixed with men is allocution, and a large degree of subjectivity is involved. "The speaker resorts to men whenever he has grounds to view several persons as a group, either relative to himself or relative to a third party," and that is why Iljic proposes to call nouns suffixed with men " 'personal' collective[s]," analogous to the term " "personal' pronoun" (1994:96). Iljic argues further that even in the pronominal system, men is not a plural suffix but a collective marker. The Chinese pronominal system consists of wo '1 $1 \mathrm{sg}$ ', $n i$ ' $2 \mathrm{sg}$ ', and $t a$ ' $3 \mathrm{sg}$ ' and the same elements suffixed with men for 1pl, 2pl, and 3pl, respectively. According to Iljic (1994:97), however, " $[\mathrm{t}]$ he so-called 'plural' of personal pronouns is not an addition or a multiplication of elements, but a grouping of entities into one whole according to their position relative to the origin." He continues, "We does not amount to several $I$ 's . . . but to a group in the name of which $I$ speaks."'

We would like to point out that as a collective marker, men is far from unique. Such markers have been reported for Ewe, Icelandic, and Afrikaans (Den Besten 1996). Afrikaans, for instance, has the element hulle 'them', whose function is similar to that of men. Den Besten (1996) shows that it is not a plural morpheme; instead, he uses terms like "associative" and "group plural," very reminiscent of the terms Iljic uses in writing about Chinese men. Thus, (54a) does not mean 'dads' but 'dad and his folks; dad and another person, especially mom: my parents'. Den Besten also argues that hulle 'them' is not a plural marker because it can be attached to plural nouns and conjoined phrases, as illustrated in (54b) and (54c), respectively ((54a-c) are taken from Den Besten 1996:14-15).

(54) a. pa-hulle dad-them 'dad and his folks; dad and another person, especially mom: my parents'

b. die kinders-hulle the children-them 'the children and possibly one or two other persons associated with them'

c. Piet en Koos-hulle

Piet and Koos-them

'Piet and Koos and their folks; Piet and Koos and possibly one or two other persons associated with them' 
In short, the element men is not a plural marker; Chinese has no number morphology expressed on the noun.

In sum, the superstructure of NP involves a number of functions, which can be expressed in different ways; that is, they can be expressed by separate morphemes, or they can cluster in several ways, as a result of which one morpheme may express several of them. The French determiner possibly has a subordinative function in addition to expressing classification and number. In Chinese the classifier is similar: it expresses both classification and number, at the same time performing the deictic/subordinative function.

\section{Some Implications}

Our analysis of bare nouns and $[\mathrm{Cl}+\mathrm{N}]$ phrases has clear implications for the analysis of other elements in Chinese, notably pronouns and demonstratives. We will comment briefly on these elements, starting with pronouns. We have indicated that noun phrases are CIPs or NumeralPs. What about pronouns? Pronouns in languages such as English have been considered to be basegenerated in D (e.g., Postal 1969, Longobardi 1994). We have shown that Chinese definite noun phrases are not DPs but CIPs. Clearly, pronouns are not classifiers and thus, they cannot be basegenerated in $\mathrm{Cl}$. However, there is no doubt that pronouns in Chinese are also definite and that they do not have distributional restrictions like indefinite noun phrases. As a consequence, we must assume that pronouns are base-generated as Ns and undergo movement to $\mathrm{Cl}$. This assumption is supported by the fact that pronouns in Chinese are similar to proper names in that they can be preceded by numerals and classifiers.

(55) Cong nei-ge jing-zi, wo keyi kandao wu-ge wo.

from that-CL mirror I can see five-CL I

'From that mirror, I can see five copies of myself (five I's/me's).'

As (55) shows, the pronoun wo 'I' can be used alone, and it can also be preceded by a numeralclassifier sequence. When the pronoun is used alone, it has moved from $\mathrm{N}$ to $\mathrm{Cl}$, just like a proper name.

Next we turn to demonstratives (see (36)). As mentioned earlier, Tang (1990) regards Chinese demonstratives as instances of D. However, it is not clear that demonstratives are really Ds, dominating NumeralP. Bernstein (1997), for example, generates them in a specifier position of an XP lower than DP. More generally, there are many languages, such as Arabic and Greek, in which demonstratives and Ds/determiners cooccur. In other languages the demonstratives are the same as the words for 'here' and 'there' (e.g., 'this book' comes out as 'the book here' or 'the here book'). As examples, Bernstein cites such diverse languages as Spanish (see (56a)), Javanese, and colloquial varieties of Swedish and Norwegian (one of her colloquial Norwegian examples is given in (56b)).

(56) a. el hombre este

the man this

'this man' 
b. den herre klokka

the here watch-the

'this watch'

The Chinese demonstratives are also basically locative elements. Noting that there is no reason to assume that they necessarily occur in $\mathrm{D}$, we will leave the demonstratives and what position they occupy as topics for future research.

It should be noted that in our account of the interpretation of noun phrases in Cantonese and Mandarin, the lack of articles plays a major role as well. We have assumed that there is also a count/mass distinction in these two languages. Because number morphology is lacking, Chinese count nouns are count mass nouns, the count/mass distinction being syntactically reflected in the classifier system. The distinctive property of Cantonese and Mandarin that bare nouns can have various interpretations is in fact due to the lack of articles. Because of this lack, nothing blocks the use of the 1 operator and the $\cap$ operator, the former yielding a definite interpretation, the latter a kind interpretation (see Chierchia 1998 for such an account of Russian, which also lacks articles). This makes a clear distinction between languages with articles and those without (e.g., Chinese): only the latter will allow bare nouns to have various interpretations.

The lack of articles combined with the use of classifiers leads to another difference between article-less and articled languages. In Cantonese and Mandarin, indefinite noun phrases require the presence of numerals. The NumeralP, being a quantificational expression, is interpreted as indefinite. This is not the case in articled languages. As suggested by Teun Hoekstra (personal communication; class lectures, fall 1996), Germanic and Romance nominals are quantificational expressions, that is, indefinite, unless they are embedded in a DP. Thus, the book in English is in fact the [a book]. Hoekstra links this to the deictic discourse function of D: only with D can a speaker refer to a specific instance of the thing denoted by $\mathrm{N}$.

A question that arises is how Chinese languages express phrases like 'the three students', bearing in mind that English does this by combining the definite article with a numeral + noun sequence. Let us use Mandarin examples to answer this question. There are two ways to express 'the three students' in Mandarin, as shown in (57).

(57) a. Na san-ge xuesheng lai-le. that three-CL student come-LE 'Those three students came.'

b. San-ge xuesheng dou lai-le. three-CL student all come-LE 'All three students came.'

The sentence in (57a) shows that one way to make a numeral phrase definite is by adding a demonstrative. The sentence in (57b) shows an apparent counterexample to the widely held claim that indefinite noun phrases cannot occur in preverbal positions. Note however that the universal quantifier dou 'all' is present and the sentence is interpreted as 'for all $x, x$ is a member of three students, $x$ came'. Thus, the noun phrase (57b) is strictly speaking not the equivalent of 'the three students'. 


\section{References}

Au Yeung, Ben. 1997. A parametric analysis of Cantonese and Mandarin nominals. In Proceedings of Postgraduate Research Forum on Language and Linguistics, 186-197. City University of Hong Kong and Chinese University of Hong Kong.

Barwise, Jon, and John Etchemendy. 1986. The liar: An essay on truth and circularity. Oxford: Oxford University Press.

Bernstein, Judy. 1997. Demonstratives and reinforcers in Romance and Germanic languages. Lingua 102: $87-113$.

Besten, Hans den. 1996. Associative DPs. In Linguistics in the Netherlands 1996, ed. Crit Cremers and Marcel den Dikken, 13-24. Amsterdam: John Benjamins.

Bunt, Harry. 1985. Mass terms and model-theoretic semantics. Cambridge: Cambridge University Press.

Chao, Yuen-Ren. 1968. A grammar of spoken Chinese. Berkeley and Los Angeles: University of California Press.

Cheng, Lisa L.-S., and Rint Sybesma. To appear. Yi-wan tang, yi-ge tang: Classifiers and massifiers. TsingHua Journal of Chinese Studies.

Chierchia, Gennaro. 1995. Plurality of mass nouns and the notion of "semantic parameter.” Ms., University of Milan.

Chierchia, Gennaro. 1998. Reference to kinds across languages. Natural Language Semantics 6:339-405.

Chomsky, Noam. 1995. The Minimalist Program. Cambridge, Mass.: MIT Press.

Croft, William. 1994. Semantic universals in classifier systems. Word 45:145-171.

Delfitto, Denis, and Jan Schroten. 1991. Bare plurals and the number affix in DP. Probus 3:155-185.

Diesing, Molly. 1992. Indefinites. Cambridge, Mass.: MIT Press.

Doetjes, Jenny. 1996. Mass and count: Syntax or semantics? In Proceedings of Meaning on the HIL, 34-52. (HIL Occasional Papers in Linguistics 1.) HIL/Leiden University.

Doetjes, Jenny. 1997. Quantifiers and selection: On the distribution of quantifying expressions in French, Dutch and English. Doctoral dissertation, Leiden University.

Frank, Steven. 1994. Parametric properties of numeral phrases in Slavic. Natural Language \& Linguistic Theory 12:597-674.

Greenberg, Joseph. 1963. Universals of language. Cambridge, Mass.: MIT Press.

Higginbotham, James. 1985. On semantics. Linguistic Inquiry 16:547-593.

Huang, C.-T. James. 1987. Existential sentences in Chinese and (in)definiteness. In The representation of (in)definiteness, ed. Eric Reuland and Alice ter Meulen, 226-253. Cambridge, Mass.: MIT Press.

Ikoro, Suanu. 1994. Numeral classifiers in Kana. Journal of African Languages and Linguistics 15:7-28.

Iljic, Robert. 1994. Quantification in Mandarin Chinese: Two markers of plurality. Linguistics 32:91-116.

Krifka, Manfred. 1992. Thematic relations as links between nominal reference and temporal constitution. In Lexical matters, ed. Ivan Sag and Anna Szabolcsi, 29-53. Stanford, Calif.: CSLI Publications. [Distributed by Cambridge University Press.]

Krifka, Manfred. 1995. Common nouns: A contrastive analysis of Chinese and English. In The generic book, ed. Gregory Carlson and Francis Pelletier, 398-411. Chicago: University of Chicago Press.

Krifka, Manfred, Francis Pelletier, Gregory Carlson, Alice ter Meulen, Godehard Link, and Gennaro Chierchia. 1995. Genericity: An introduction. In The generic book, ed. Gregory Carlson and Francis Pelletier, 1-124. Chicago: University of Chicago Press.

Kripke, Saul. 1972. Naming and necessity. In Semantics of natural language, ed. Donald Davidson and Gilbert Harman, 253-355. Dordrecht: Reidel.

Landman, Fred. 1989. Groups, I. Linguistics and Philosophy 12:559-605.

Landman, Fred. 1991. Structures for semantics. Dordrecht: Kluwer.

Leung, Chung-Sum. 1980. Guo-yue yu bijiao yufa zhaji-dingzhi zhishici (Notes on comparative grammar 
of Mandarin and Cantonese-markers of definiteness). Zhong-Ying Yuwen Xue-Yan (Language Learning and Research) 1:15-28.

Li, Charles, and Sandra Thompson. 1975. The semantic function of word order: A case study in Mandarin. In Word order and word order change, ed. Charles N. Li, 163-186. Austin: University of Texas Press.

Li, Charles, and Sandra Thompson. 1981. Mandarin Chinese: A functional reference grammar. Berkeley and Los Angeles: University of California Press.

Li, Yen-hui Audrey. 1998. Argument determiner phrases and number phrases. Linguistic Inquiry 29:693-702. Longobardi, Giuseppe. 1994. Reference and proper names. Linguistic Inquiry 25:609-666.

Longobardi, Giuseppe. 1996. The syntax of N-raising: A minimalist theory. (OTS Working Papers OTSWP-TL-96-005.) OTS, Utrecht University.

Lü, Shuxiang. 1947. Zhongguo wenfa yaolüe (Outline of Chinese grammar). Shanghai: Shangwu.

Matthews, Stephen, and Patrizia Pacioni. 1996. Specificity and genericity of NPs in Cantonese and Mandarin. Paper presented at the Symposium on Referential Properties of Chinese Noun Phrases, City University of Hong Kong.

Matthews, Stephen, and Virginia Yip. 1994. Cantonese: A comprehensive grammar. London: Routledge.

Mullie, Jos. 1930. Het Chineesch taaleigen: Inleiding tot de gesproken taal (Noord-Pekineesch dialekt) (The Chinese language: Introduction to the spoken language (North Peking dialect)). Peking [Pei-p'ing]: Drukkerij der Lazaristen.

Pan, Hai-Hua. 1990. Head noun movements in Chinese, the ECP and minimality. Ms., University of Texas, Austin.

Paris, Marie-Claude. 1981. Problèmes de syntaxe et de sémantique en linguistique chinoise (Problems of syntax and semantics in Chinese linguistics). Collège de France, Paris.

Paris, Marie-Claude. 1989. Linguistique générale et linguistique chinoise: Quelques exemples d'argumentation (General linguistics and Chinese linguistics: Some examples of argumentation). UFRL, Université Paris 7, Paris.

Partee, Barbara. 1987. Noun phrase interpretation and type-shifting principles. In Studies in Discourse Representation Theory and the theory of generalized quantifiers, ed. Jeroen Groenendijk and Martin Stokhof, 115-143. Dordrecht: Foris.

Peyraube, Alain. 1998. On the history of classifiers in archaic and medieval Chinese. In Studia linguistica serica, ed. Benjamin T'sou, 39-68. City University of Hong Kong, Hong Kong.

Postal, Paul. 1969. On so-called "pronouns" in English. In Modern studies in English, ed. David Reibel and Sanford Schane, 201-224. Englewood Cliffs, N.J.: Prentice-Hall.

Ritter, Elizabeth. 1989. A head-movement approach to construct-statenoun phrases. Linguistics 26:909-929.

Ritter, Elizabeth. 1991. Two function categories in noun phrases: Evidence from Modern Hebrew. In Perspectives on phrase structure: Heads and licensing, ed. Susan D. Rothstein, 37-62. San Diego, Calif.: Academic Press.

Shyu, Shu-Ing. 1996. The syntax of focus and topic in Mandarin Chinese. Doctoral dissertation, University of Southern California, Los Angeles.

Stowell, Tim. 1989. Subjects, specifiers, and X-bar theory. In Alternative conceptions of phrase structure, ed. Mark R. Baltin and Anthony S. Kroch, 232-262. Chicago: University of Chicago Press.

Sybesma, Rint. 1992. Causatives and accomplishments: The case of Chinese ba. Doctoral dissertation, HIL/Leiden University.

Sybesma, Rint. 1999. The Mandarin VP. Dordrecht: Kluwer.

Szabolcsi, Anna. 1987. Functional categories in the noun phrase. In Approaches to Hungarian 2, ed. Istvan Kenesei, 167-190. Szeged: JATE.

Szabolcsi, Anna. 1994. The noun phrase. In Syntax and semantics 27: The syntactic structure of Hungarian, ed. Ferenc Kiefer and Katalin Kiss, 179-274. San Diego, Calif.: Academic Press. 
Tai, James, and Lianqing Wang. 1990. A semantic study of the classifier tiao. Journal of the Chinese Language Teachers Association 25:35-56.

Tang, C.-C. Jane. 1990. Chinese phrase structure and the extended $X^{\prime}$-theory. Doctoral dissertation, Cornell University, Ithaca, N.Y.

Travis, Lisa. 1984. Parameters and effects on word order variation. Doctoral dissertation, MIT, Cambridge, Mass.

Tsai, W.-T. Dylan. 1994. On economizing the theory of A-bar dependencies. Doctoral dissertation, MIT, Cambridge, Mass.

Tsai, W.-T. Dylan. 1998. Subject specificity, copy theory, and the extended mapping hypothesis. In MIT working papers in linguistics 25: The interpretive tract, 1-28. MITWPL, Department of Linguistics and Philosophy, MIT, Cambridge, Mass.

(Cheng)

Department of Linguistics

3151 Social Science Plaza

University of California, Irvine

Irvine, California 92697-5100

llcheng@uci.edu

(Sybesma)

Department of General Linguistics

Leiden University

P.O. Box 9515

2300 RA Leiden

The Netherlands

sybesma@rullet.leidenmiv.nl 